\title{
Super-Capacitors as an Alternative for Renewable Energy Unstable Supply
}

\author{
${ }^{1}$ Collins INENEJI, ${ }^{2}$ Olusola BAMISILE, ${ }^{3}$ Mehmet KUŞAF \\ ${ }^{1}$ Department of Computer Engineering, ${ }^{2}$ Department of Energy Systems Engineering, \\ ${ }^{3}$ Departmentof Electrical and Electronic Engineering \\ Faculty of Engineering, Cyprus International University, Haspolat-Lefkoşa, \\ Turkish Republic of Northern Cyprus,Turkey
}

\begin{abstract}
In this article a Lithium battery and super-capacitors performance for energy storage in renewables is compared. A photovoltaic system is considered with Lithium-ion (Li-ion) battery, then with a supercapacitor compared as the storage device. The super-capacitor consists of 10 capacitors connected in series and one in parallel. The comparison is made based on the state of charge and the output voltage of the two storage devices. Matlab/Simulink model is developed to make the analysis of the two systems. Li-ion battery displayed a uniform voltage of $0.9 \mathrm{~V}$ while the super-capacitor accumulated $250 \mathrm{~V}$; when the simulation was done within a specific time frame. The Hybrid system however, drew a lower voltage of $15 \mathrm{~V}$ but a more stable supply is achieved over time. While the state of charge of the battery is constant over the time of simulation, the supercapacitor increases with time.
\end{abstract}

Key words: Super-capacitor, battery, renewable energy, photovoltaic

\section{Introduction}

One of the most promising devices in the future of energy storage are super-capacitors [1,2]. Capacitors, as an energy storage device have 100-1000 times lesser electrochemical double-layer (ultra-capacitor/super-capacitor) in terms of energy density [2]. Super-capacitors have been widely analyzed as an innovative storage elements because of their higher energy and power densities [3-5]. Electrochemical double-layer capacitors (which are categorized as a type of supercapacitors) have excellent physical and chemical properties of carbonaceous materials i.e. high conductivity, relatively large specific surface area, low cost and good temperature stability $[1,6$, 7].

Recently, lots of research have been done to investigate the durability and versatility of supercapacitors. Authors of [8] published a comparative study of super-capacitors, li-ion battery and non-aqueous asymmetric hybrid devices. These devices are designed for automotive applications, two components are found to have high visibility performance between different devices [8]. Electrochemical pulse deposition of Ni nano particles was considered by authors in. A pulse-mode deposition technique was used to deposit homogenous and dense Ni nano particles on 3D grapheme network. The CNFs/3DGN hybrid nano-architecture has an excellent specific capacitance and possesses large surface area when tested as electrode for super-capacitor. Also, some electrochemical studies were done on corncob for super-capacitors applications. The application is mainly for aqueous/non-aqueous electrolytes and the research is done among three different ionic

*Corresponding author: Address: Faculty of Engineering, Department of Computer Engineering, Cyprus International University, 99258, Lefkoşa, Mersin 10 TURKEY. E-mail address: cineneji@ciu.edu.tr, Phone: +905428791587 
liquids. Corncob derived activated carbon components are concluded to be promising materials for applications in super-capacitors [9]. Similar studies [10] done on super-capacitors includes some recent developments in super-capacitors. In [11-15] authors worked on performance evaluation of super-capacitors while some did comparison analysis of super-capacitors to other storage devices. In most of the literature, specific application and performance evaluation of super capacitors for specific renewable energy storage system was inadequate. Although authors of [16] worked on capacitive energy storage using liquid-mediated materials, publication on explicit analysis of super-capacitors on different renewable energy are few. Researches of [17-21] all studied the performance of super-capacitors for energy storage with different applications. The literature study indicates that none of the publications involves intrinsic performance analysis on the charging and discharging capability of super-capacitors as energy storage for photovoltaic systems. The closest of all the literatures is [22], in which the performance of photovoltaic standalone system is studied. Battery-super-capacitor combination was used as the storage device for the system [23]. This research paper presents an analysis on the gain in energy losses, the rms current gain in battery, elimination rage of load power and total energy efficiency. Extensive analysis on super-capacitor ability is very important since it helps to stabilize solar photovoltaic systems.

This study is focused on analysis of li-on battery in comparison with super-capacitors on a solar photovoltaic system. The effect of super-capacitors and li-on battery on the voltage output and the state of charge of the system are intrinsically analyzed.

\section{Materials and Method}

PV modules and voltage characteristics, li-ion battery with characteristic model and supercapacitor ratings are described in this section. The proposed circuits which shows the use of battery and super-capacitor are also given. These circuits' outputs highlight the stability in supply of energy.

The Simulink PV panel is composed of modules (1Soltech 1STH-215-P), which consists of smaller cells, with characteristics shown in Table 1. The modules are either in parallel strings or seriesconnected strings, depending on the voltage or current demand. In this simulation, 10 modules are connected in series and 40 modules are in parallel. Where the module photo-current $\left(\mathrm{I}_{\mathrm{ph}}\right)$ is as shown in equ(1) [24-26]:

$$
I_{p h}=\left[I_{s c}+K_{i}(T-298)\right] \frac{I_{r}}{100}
$$

Where $I_{p h}$ is the photo-generated current, $I_{s c}$ is the short-circuit current, $K_{i}$ is the short-circuit temperature coefficient, $\mathrm{T}$ is the surface temperature of the PV cells, and $\mathrm{I}_{\mathrm{r}}$ is the reference current. 
Table 1a PV modules electrical characteristics

\begin{tabular}{|c|c|c|}
\hline \multirow{12}{*}{ 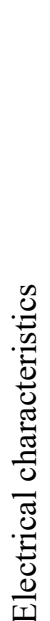 } & STC Power Rating $\mathrm{P}_{\mathrm{mp}}(\mathrm{W})$ & 215 \\
\hline & PTC Power Rating $\mathrm{P}_{\mathrm{mpp}}(\mathrm{W})$ & 189.4 \\
\hline & PTC/STC Power Ratio & $88.1 \%$ \\
\hline & Open Circuit Voltage $V_{o c}(V)$ & 36.3 \\
\hline & Short Circuit Current $\mathrm{I}_{\mathrm{sc}}(\mathrm{A})$ & 7.84 \\
\hline & Voltage at Maximim Power $V_{m p}(V)$ & 29.0 \\
\hline & Current at Maximim Power $\mathrm{I}_{\mathrm{mp}}(\mathrm{A})$ & 7.35 \\
\hline & Panel Efficiency & $13.7 \%$ \\
\hline & Fill Factor & $75.5 \%$ \\
\hline & Power Tolerance & $-3.00 \% \sim 3.00 \%$ \\
\hline & Maximum System Voltage $V_{\max }(\mathrm{V})$ & 600 \\
\hline & Maximum Series Fuse Rating (A) & 15 \\
\hline
\end{tabular}

\subsection{The lithium-ion (li-ion) battery}

The li-ion battery is made up of carbon and the cathode. It is formed differently from metallic oxide compounds, with the electrolyte made up of lithium salts (atomic number 3 ). It is a preferable material compared with others, since it is the most electro-negative and the lightest metal, with high energy density and produces high terminal voltage. The characteristic of li-ion battery is shown in Table 2. However, it could be very hazardous and costly to be produced because of the temperature sensitivity of its production. These batteries operate between $2.5 \mathrm{~V}$ to $3.5 \mathrm{~V}$ with high pulse current of up to $35 \mathrm{~A}$.

Table 2 Li-ion battery characteristics

\begin{tabular}{ll}
\hline Parameter & Value \\
\hline Nominal capacity (V) & 3.35 \\
Rated capacity (Ah) & 2.05 \\
İnitial State-of-Charge (\%) & 100 \\
Battery response time (s) & 30 \\
Maximum capacity (Ah) & 2 \\
Fully Charged Voltage (V) & 4.2 \\
Nominal Current Discharge (mA) & 1.95 \\
Internal resistance (m ohms) & 0.0165 \\
Capacity (Ah) at nominal voltage & 1.81 \\
\hline
\end{tabular}

\subsection{Super-capacitor}

The capacitance of a capacitor plays a very important role and therefore, the need for accurate and systematic connection in parallel or series as the storage capacitor cannot be over-emphasized. 
These large storage designs are used in such systems where there is very high consumption required projects such as transmission energy or renewable energy conversion [27]. This design provides solution to the large amount of energy which is needed to be stored within a very short period, with minimal time range. Super-Capacitor ratings are given in Table 3. Renewable energy which sometimes produces unstable power can be stabilized by the capacitance of the capacitor, thereby ensuring constant power and maximum energy [28-31]. The capacitance as stated in [9] is expressed mathematically as;

$$
C_{S C}=\frac{2 E_{S c}}{\eta V_{\max }^{2}\left[1-\left(\frac{\vartheta}{100}\right)^{2}\right]}
$$

Figure 1 shows the charge profile of the super-capacitor for different currents as a function of time. In order to highlight the steadiness of the power using the super-capacitors, two circuits are designed which are given in the next section. The first one is a solar panel connected to a charging circuit that uses a simple battery to store energy, and the other one consists of a super-capacitor as a replacement for the battery in one circuit.

Table 3 Super-capacitor rating

\begin{tabular}{ll}
\hline Parameter & Value \\
\hline Rated capacitance $(\mathrm{mF})$ & 100 \\
Equivalent DC series resistance (Ohms) & 0.0021 \\
Rated voltage $(\mathrm{V})$ & 6 \\
Number of series capacitors & 10 \\
Number of parallel capacitors & 1 \\
Initial voltage $(\mathrm{V})$ & 0 \\
Operating temperature (Celsius) & 25 \\
\hline
\end{tabular}

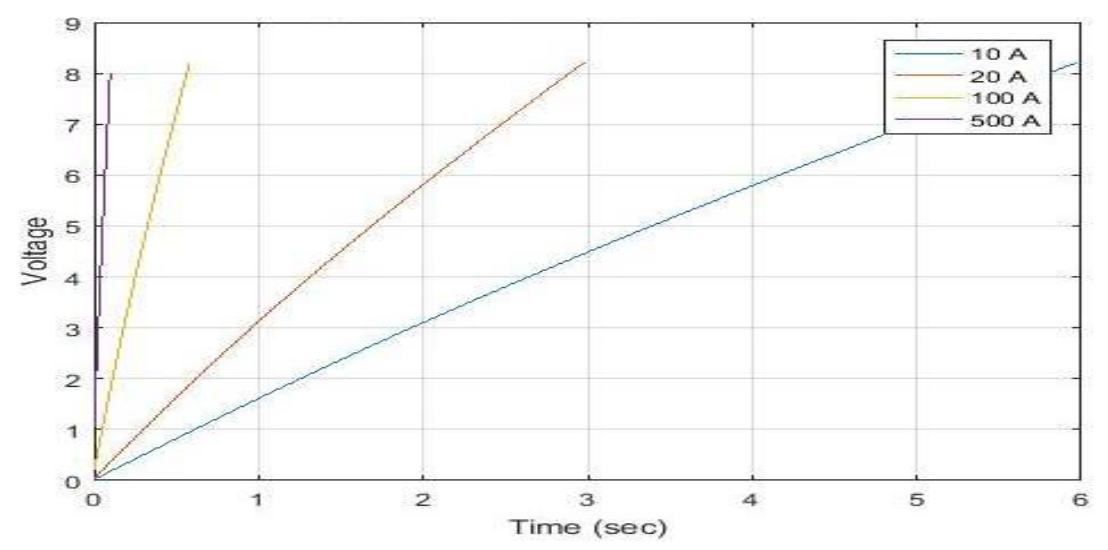

Figure 1. Charge profile of the super-capacitor

\section{Designs of the super-capacitor and the battery circuits}

$\mathrm{R}$ The design and simulations are carried out using the MATLAB/Simulink. The equivalent model 
for the battery is represented in Figure 2, in which the battery is used as a storage and transmission device. Where the irradiance is fixed to be $1000 \mathrm{~W} / \mathrm{m}^{2}$ irradiance, and the temperature to be $25^{\circ} \mathrm{C}$. Power is transmitted through the battery, where it stores charge for a while and after its filled up, it starts to supply a nominal current of $0.44 \mathrm{~A}$.

Figure 3 displays the proposed super-capacitor circuit. This circuit is supplied by the same amount of input power, (given in the calculation section) but with the advantage of the super-capacitor, more power is generated in a short time and discharged equally in a similar short time.

Figure 4 and Figure 5 display the major difference between the usage of both materials for charge and discharge activities. The battery delivers a uniform voltage of $0.9 \mathrm{~V}$ for less than one sec, however super-capacitor, with just 10 capacitors connected in series and 1 parallel, it accumulates as much as $250 \mathrm{~V}$ and above in just less than one sec. this difference explicitly shows the advantage of the super-capacitor.

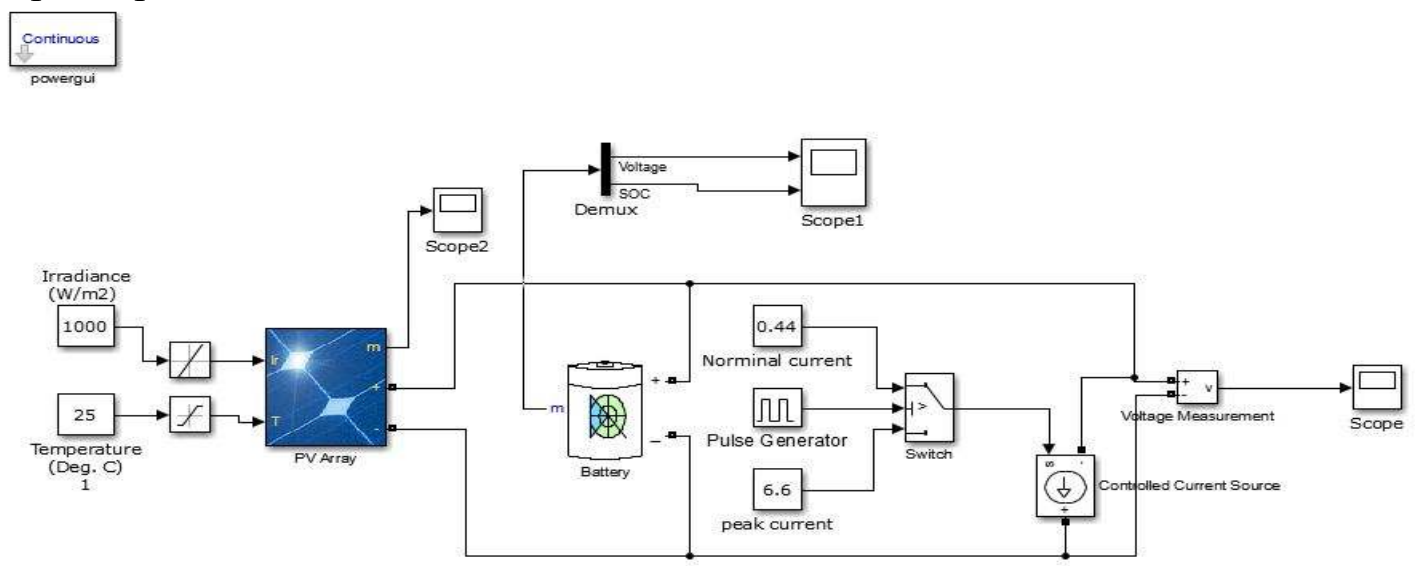

Figure 2. Circuit Diagram for the system with lithium-on battery

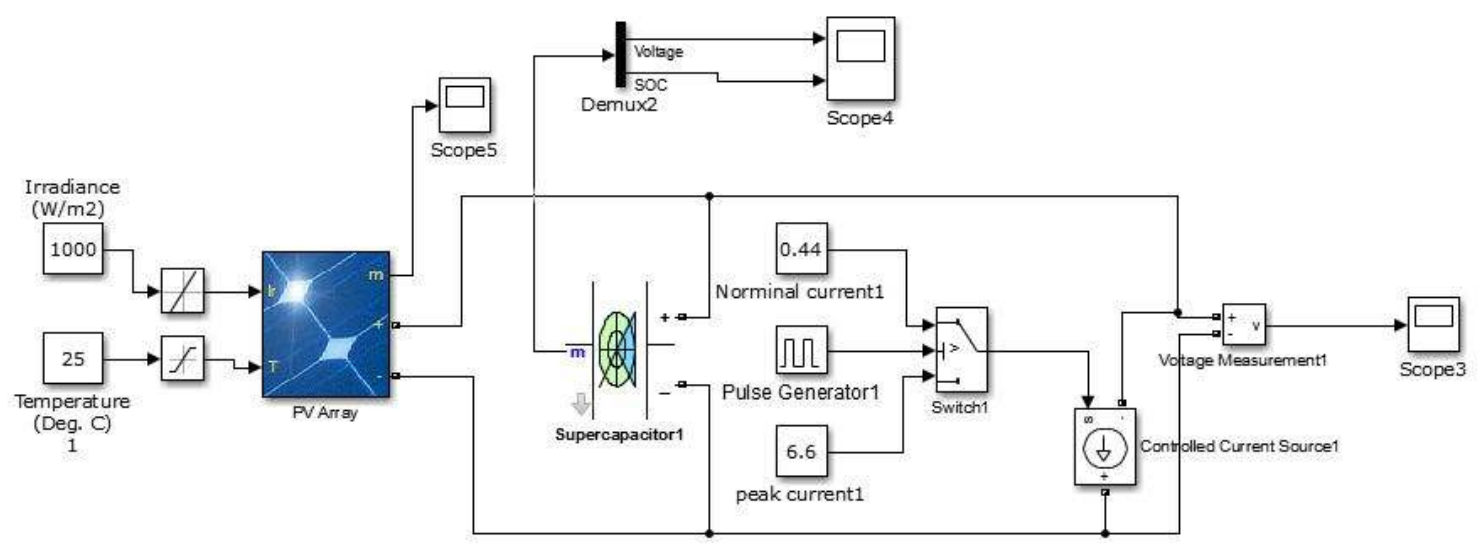

Figure 3. Circuit diagram for the system with super-capacitor 


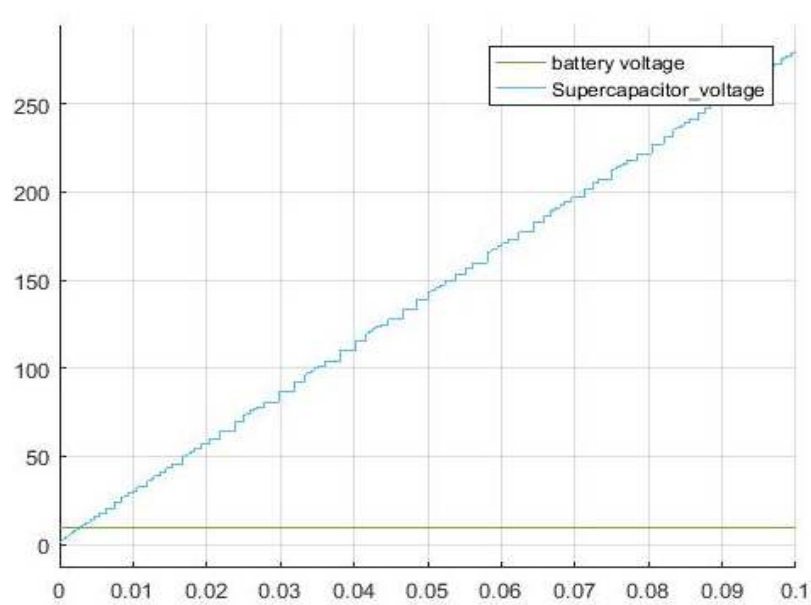

Figure 4. Output voltage comparison between the battery and super-capacitor

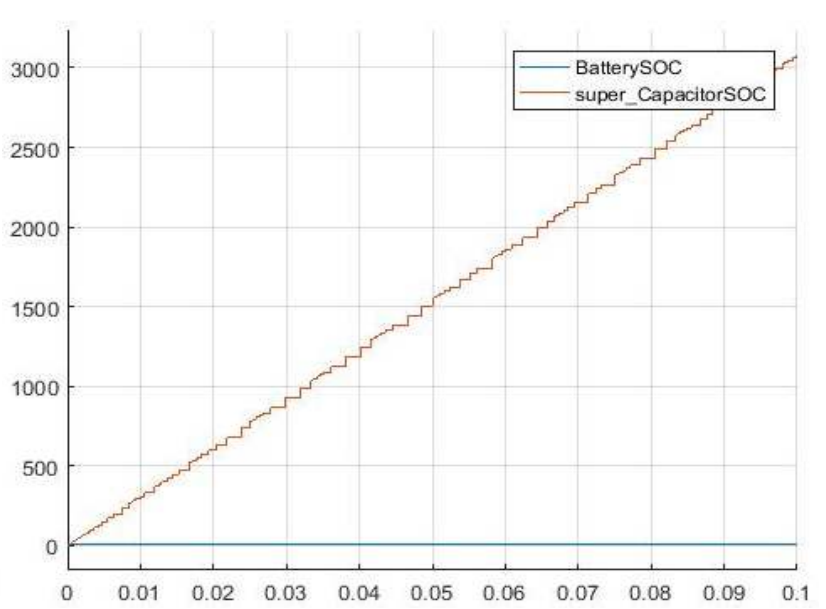

Figure 5. State of Charge comparison between the battery and the super-capacitor

\section{Hybrid system (charging super-capacitors and battery together)}

As shown in the new model, i.e. Figure 6, super-capacitor is used at power generation for systematic smoothening of the peak, value of the generated voltage during periodic transients in power. Due to this, the new system design can supply full load power whenever there is power shortage due to peak discharge or system failure. The two systems (namely super-capacitor and battery circuits) are combined, to share the load of power in which the battery remains the main device in the system, while the super-capacitor performs the back-up task.

Therefore, battery cells last longer, as it reduces demand of the load power on the battery cells, by bearing the power load periodically. As shown in Figure 7, the super-capacitor acts as a connector and stabilizer between a capacitor and a battery because of its efficient charge and discharge characteristics.

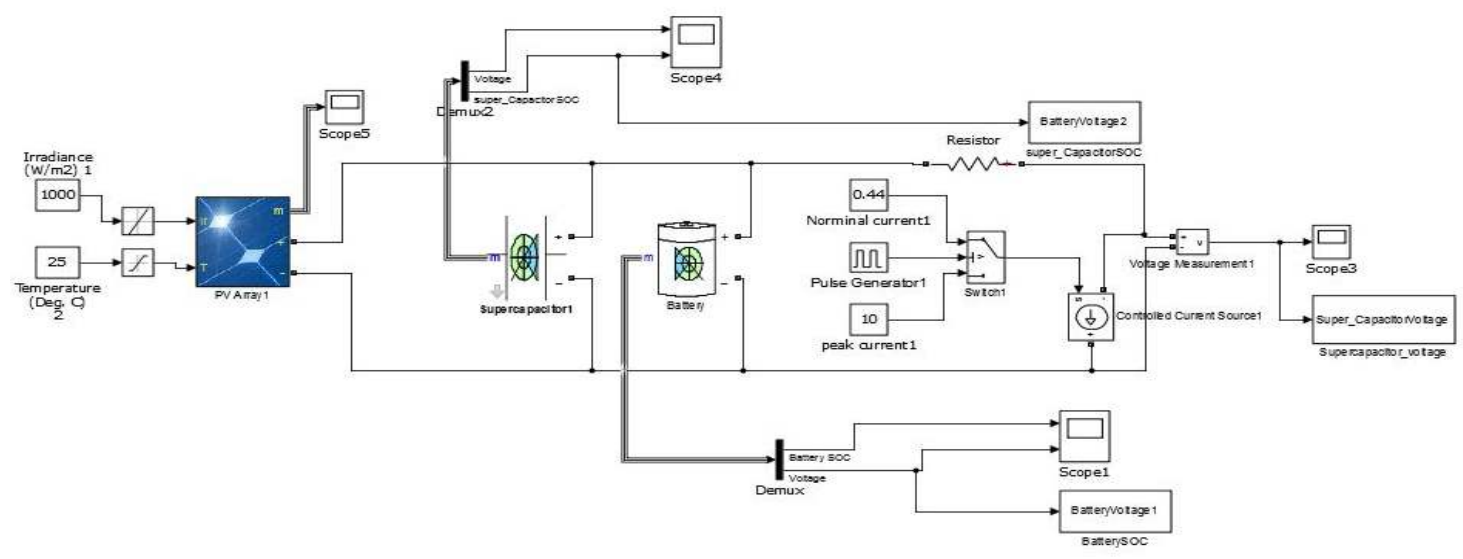

Figure 6. Hybrid system 


\section{Results and calculations}

The invention and usage of the super-capacitor replaces ordinary battery and capacitor, as the energy sector tilts to renewable energy for cheaper and affordable energy and power source. The unstable supply of power and energy has caused researchers to investigate the applications of supercapacitor for stability. Even though, it has short charge and discharge time, it plays important role to achieve stable distribution in a very short time.

The voltage range of the capacitor has been calculated which is defined by the predetermined nominal voltage and the maximum voltage. Here the nominal and output voltages are $0 \mathrm{~V}$ and 15 $\mathrm{V}$ respectively. The system remains at $0 \mathrm{~V}$, and the energy stored can be accessed and utilized. Capacitance of the circuit; to determine the capacitance of the circuit, we apply the equations below as in [25],

$$
C=\frac{E_{L O A D^{* 2}}}{\left(V_{M A X}{ }^{2}-V_{M I N}{ }^{2}\right)}
$$

Where the $\mathrm{E}_{\mathrm{LOAD}}$ is the energy from the load. The power supplied by the PV array is fixed to be $200 \mathrm{~kW}$ by using equation 3 , therefore the energy of the circuit becomes, $\frac{k W}{h}=\frac{200}{60}=3.33 \mathrm{~kW} / \mathrm{h}$ and the capacitance becomes $C=\frac{3.33 * 2}{15^{2}}=0.0296 \mathrm{~F}$.

Resistance of the Circuit; being the voltage across the circuit divided by the current,

$$
R=\frac{\Delta V}{I}=\frac{15}{10}=1.5 \Omega
$$

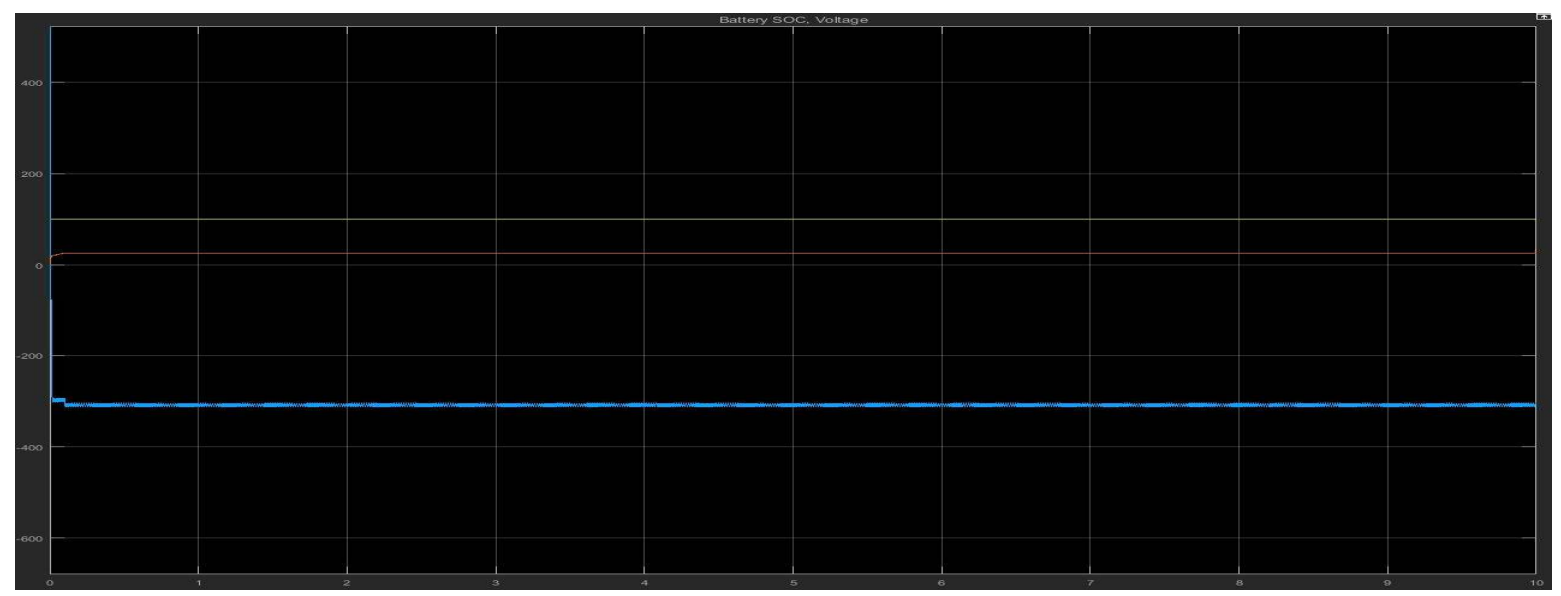

a 


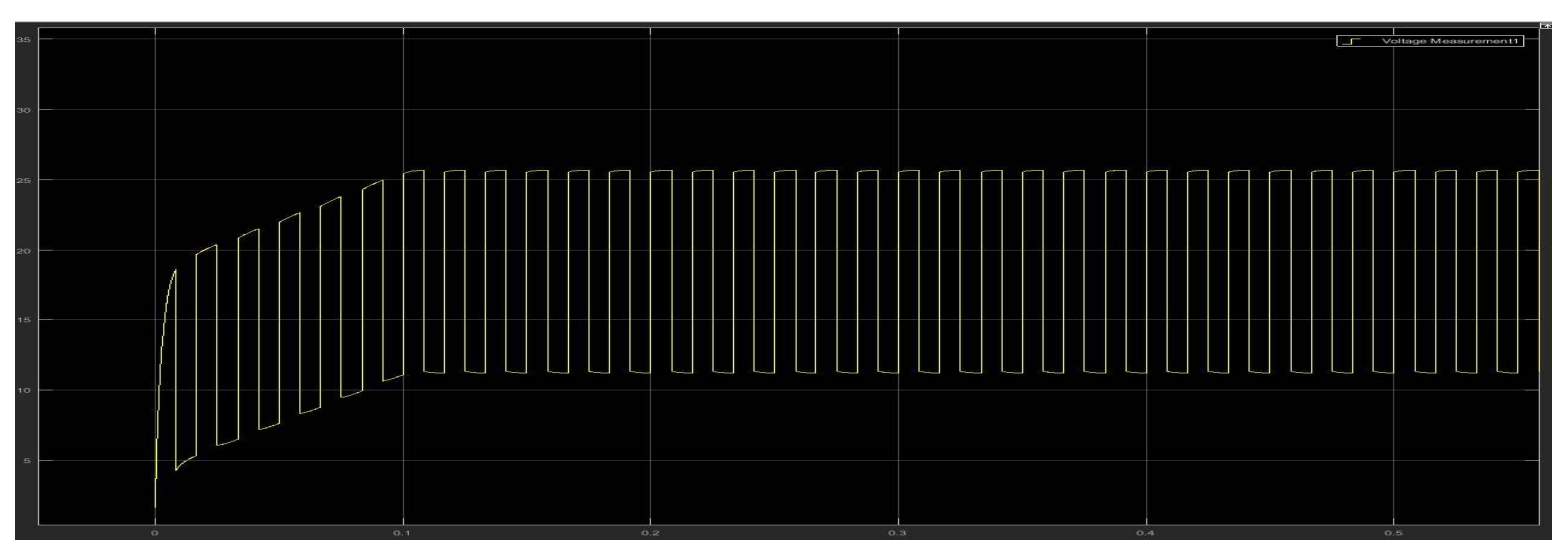

b

Figure 7.a) Super-capacitor state of charge and output voltage, b)Output voltage after increase in load current from $6.6 \mathrm{~A}$ to $10 \mathrm{~A}$

As shown figure. 7 , the output voltage gradually increases from the nominal voltage, $0 \mathrm{~V}$ to $15 \mathrm{~V}$ where it becomes a steady supply. The output voltage however oscillates between $12 \mathrm{~V}$ and $27 \mathrm{~V}$, which is the originally designed rating for the circuit.

The hybrid system indicates, the importance of capacitance towards smoothening and backup of power supply.

\section{Conclusions}

A Simulink model has been developed to study the use of super-capacitor in place of Li-ion battery for a PV-system. The simulation circuits are designed to implement the state of charge and voltage output. Ten capacitors were connected in series and one in parallel in order to make up the supercapacitor.

The Li-ion battery displays a uniform voltage of $0.9 \mathrm{~V}$ while the super-capacitor accumulated as much as $250 \mathrm{~V}$ with the same time frame. The simulation results validate that super-capacitors are a better storage element than batteries. The state of charge of the two storage systems further proves that super-capacitors is much better than Li-ion batteries. The combination of both systems, however, shows the interdependency and increase efficiency without negatively affecting the life span of the battery.

As the renewable energy sector seeks and scientists search for lasting solution to the storage of electricity produced, super-capacitors is one of the leading candidates to solve this problem. Although the techno-economic analyses of these systems are not mention, studies have been done in that aspect. Currently, there are super-capacitors that are feasible economically when compared to batteries in general.

\section{References}


[1] Lin, Che-hsien, Tsai C.H., Tseng F. G., Chen I. C., Hsieh C. K. Electrochemical pulse deposition of ni nanoparticles on the 3D graphene network to synthesize vertical CNFs as the full-carbon hybrid nanoarchitecture for supercapacitors. Materials Letters 2017; 192 : 40-43.

[2] N. He, Yildiz O., Pan Q., Zhu J., Z. Xiangwu, Bradford P. D., Gao W. Pyrolytic-carbon coating in carbon nano tube foams for better performance in supercapacitors. Journal of Power Sources 2017; 343: 492-501.

[3] Hou J., Cao C., Idrees F., Ma. X. Hierarchical porous nitrogen-doped carbon nanosheets derived from silk for ultrahigh capacity battery anodes and supercapacitors. ACS Nano 2015; 9: 556-2564.

[4] Candelaria S. L., Shao Y., Zhou W., Li X., XiaoJ., Zhang JiG., Wang Y., Liu J., Li J., Cao G. Nanostructured carbon for energy storage and conversion. Nano Energy 2012; 1: 195220.

[5] Faraji S., and Ani F. N. The development supercapacitor from activated carbon by electroless plating-a review. Renewable Sustainanble Energy Reviews 2015; 42: 823834.

[6] Pham D. T., Lee T. H., Luong D. H., Yao F., Ghosh A., Le V. T., Kim T. H., Li B., Chang J., and Hee L. Y. Carbon nanotube-bridged graphene 3D building blocks for ultrafast compact supercapacitors 2015; 9: 2018-2027.

[7] Wang W., Guo S., Penchev M., Ruiz I., Bozhilov K. N., Yan D., Ozkan M., Ozkan C. S. Three dimensional few layer graphene and carbon nanotube foam architectures for high fidelity supercapacitors 2013; 2: 294-303.

[8] Pasquier A. D., Irene P., Serafin M., Glenn A. A comparative study of li-ion battery, supercapacitor and nonaqueous asymmetric hybrid devices for automotive applications. Journal of Power Sources 2003;115: 171-178.

[9] Karnan M., Subramani K., Srividhya P. K., Sathish M. Electrochemical studies on corncob derived activated porous carbon for supercapacitors application in aqueous and nonaqueous electrolytes. Electrochimica Acta 2017; 228: 586-596.

[10] Liu Y., and Peng X. Recent advances of supercapacitors based on two-dimensional materials. Applied Materials Today 2017; 7: 1-12.

[11] Bui P. T. M., Song J. H., Li Z.Y., Akhtar M. S., Yang O.B. Low temperature solution processed Mn3O4 nanoparticles: enhanced performance of electrochemical supercapacitors. Journal of Alloys and Compounds 2017; 694: 560-567.

[12] Chu A., Braatz P. Comparison of commercial supercapacitors and high-power lithium-ion batteries for power-assist applications in hybrid electric vehicles initial characterization. Journal of Power Sources 2002; 112: 236-246.

[13] Quan B., Meng Y., Li L., Yao Z., Liu Z., Wang K., Wei Z., Gu C., Li J. Vertical few-layer graphene/metalized si-nanocone arrays as 3D electrodes for solid-state supercapacitors with large areal capacitance and superior rate capability. Applied Surface Science2017; 404: 238-245.

[14] Luo L., Liu T., Zhang S., Ke B., Yu L., Hussain S. Hierarchical CO3O4 @ ZnWO4 core/shell nanostructures on nickel foam: synthesis and electrochemical performance for supercapacitors. Ceramics International 2017; 43: 5095-5101.

[15] Zhou D., Wang H., Mao N., Chen Y., Zhou Y., Yin T., Xie H., Liu W., Chen S., Wang X. 
High energy supercapacitors based on interconnected porous carbon nanosheets with ionic liquid electrolyte. Microporous and Mesoporous Materials 2017, 241: 202-209.

[16] Yang X., Cheng C., Wang Y., Qiu L., Li D. Liquid-mediated dense integration of graphene materials for compact capacitive energy storage. Science 2013; 341: 534-537.

[17] Tehrani Z., Thomas D., Korochkina T., Phillips C., Lupo D., Lehtimäki S., Gethin D. Large-area printed supercapacitor technology for low-cost domestic green energy storage. Energy 2017; 118: 1313-1321.

[18] Li L., Huang Z., Li H., Peng J. A rapid cell voltage balancing scheme for supercapacitor based energy storage systems for urban rail vehicles. Electric Power Systems Research 2017; 142: 329-340.

[19] Song Z., Hou J., Hofmann H., Li J., Ouyang M. Sliding-mode and lyapunov function-based control for battery/supercapacitor hybrid energy storage system used in electric vehicles. Energy 2017; 122: 601-612.

[20] Ali Z., Tahir M., Cao C.,Mahmood A., Mahmood N., Butt F. K., TanveerM., Shakir I., Rizwan M., Idrees F., et al .. . Solid waste for energy storage material as electrode of supercapacitors. Materials Letters 2016; 181: 191-195.

[21] Lu L., Wanfei L., Lisha Z., Yijie Z., Zhao Z., Ying C., Jinghai L., Liwei L., Wei C., Yuegang Z. Impact of size on energy storage performance of graphene based supercapacitor electrode. Electrochimica Acta 2016; 219: 463-69.

[22] Cabrane Z., Ouassaid M., Maaroufi M. Analysis and evaluation of battery-supercapacitor hybrid energy storage system for photovoltaic installation. International Journal of Hydrogen Energy 2016; 41 : 20897-20907.

[23] Sharma R., and Suhag S. Novel control strategy for hybrid renewable energy-based standalone system. Turkish Journal of Electrical Engineering \& Computer Sciences 2017; 25: 2261-2277.

[24] Krismadinataa, Rahim N. Abd., Ping H. W., Selvaraj J. Photovoltaic module modeling using simulink/matlab. Procedia Environmental Sciences 2013, 17:537-546.

[25] Bellia H., Youcef R., Fatima M. A detailed modeling of photovoltaic module using MATLAB. NRIAG Journal of Astronomy and Geophysics 2014; 3: 53-61.

[26] Eteiba M. B., El Shenawy E. T., Shazly J. H., Hafez A. Z. A photovoltaic (cell, module, array) simulation and monitoring model using matlab $\mathbb{R} /$ gui interface. International Journal of Computer Applications 2013; 69:14-28.

[27] Feckl F. Efficient Super-Capacitor Charging with TPS62740. Texas USA: Texas Instruments, 2014.

[28] Patel K. R., Desai R. R. Calculation of internal parameters of super capacitor to replace battery by using charging and discharging characteristics. International Journal of Engineering and Innovative Technology 2012; 2:142-146.

[29] Sumathi S. , Kumar A. L., Surekha P. Application of matlab/simulink in solar PV systems. In: Solar PV and Wind Energy Conversion Systems. Green Energy and Technology. USA: Springer Press, 2015.

[30] Belarbi M., Boudghene-Stambouli A., Belarbi E., and Haddouche K. A new algorithm of parameter estimation of a photovoltaic solar panel. Turkish Journal of Electrical Engineering \& Computer Sciences 2016; 24: 276-284. 